\title{
Anti-mycobacterial Activity of Selected Indian Botanicals Using Surrogate Mycobacterium Strains
}

Rajesh NG $^{1^{*}}$ and Archana DJ ${ }^{2}$

${ }^{1}$ Department of Biotechnology, Savitribai Phule Pune University, Pune (MS), India

${ }^{2}$ School of Life Sciences, Swami Ramanad Teerth Marathwada University, Nanded (MS), India

*Corresponding author: Rajesh NG, Department of Biotechnology, Savitribai Phule Pune University, Pune (MS), India, Tel: 91-9423656179; E-mail: rngacche@rediffmail.com

Received date: August 05, 2017; Accepted date: August 12, 2017; Published date: August 16, 2017

Copyright: ( 2017 Rajesh NG, et al. This is an open-access article distributed under the terms of the Creative Commons Attribution License, which permits unrestricted use, distribution, and reproduction in any medium, provided the original author and source are credited.

\begin{abstract}
The aim of the present study was to validate the traditional claims of selected botanicals such as as Amorphophyllus sylvaticus, Andrographis paniculata, Corallocarpus epigaeus, Dioscorea bulbifera (L), Dioscorea oppositifolia (L), Dioscorea pentaphylla (L), Dioscorea hispida (Dennst), Enicostema axillare (Lam Raynal), Gloriosa superba (L) and Morinda citrifolia (L) as possible inhibitors of Mycobacterial strains. Different solvent extracts along with flavonoid and alkaloid fractions of the selected ten medicinal plants were evaluated for their antimycobacterial activity against Mycobacterium smegmatis (NCIM 5138) and Mycobacterium phlei (NCIM 2240). The minimum inhibitory concentrations (MICs) were calculated for determining the efficacy of the selected botanicals. As a measure of quality control, High Performance Thin Layer Chromatography (HPTLC) fingerprint of flavonoids and alkaloids of the selected plants were also developed and the $R_{f}$ values of individual samples were recorded. Amongst the tested plants only Andrographis paniculata, Morinda citrifolia, and Enicostema axillare were observed to be effective growth inhibitors of selected less virulent Mycobacterium strains, however the chloroform extract of $A$. paniculata was observed to be most effective growth inhibitor of $M$. smegmatis $(\mathrm{MIC}=10 \mathrm{mg} / \mathrm{ml}$ ) and $M$. phlei $(\mathrm{MIC}=10 \mathrm{mg} / \mathrm{ml})$. The results of the present study revealed that the botanicals like Andrographis paniculata, Morinda citrifolia, and Enicostema axillare can be considered as an important resource for the identification of novel leads against Mycobacterial strains, which perhaps can be further explored for the management of multi drug resistance in treating tuberculosis.
\end{abstract}

Keywords: Medicinal plants; Anti-mycobacterium activity; HPTLC; Mycobacterium smegmatis, Mycobacterium phlei

\section{Introduction}

Tuberculosis continues to be one of the leading infectious causes of death in the world especially in a developing and densely populated country like India. The main cause of this disease is Mycobacterium tuberculosis (M. tuberculosis). Each year 8 million people are infected by $M$. tuberculosis, and 2-3 million patients die due to TB. It has been estimated that by 2020 , nearly 1 billion people will become infected, 200 million will develop disease and 35 million will die from TB, although recent figures suggest that the global epidemic is on the threshold of decline [1]. In India the prevalence of all forms of TB is approximately estimated to be 5.05 per thousand, while the incidence of smear positive cases is around 2.27 per thousand and average annual prevalence of smear positive cases is over 84 per 100,000 [2]. Members of the genus Mycobacterium, which includes approximately over 50 species are reported to cause Mycobacterium infections [3]. The evolving emergence and spread of multi drug resistance (MDR) in $M$. tuberculosis has significantly limited the usage and efficacy of presently prescribed anti-TB drugs such as isoniazid and rifampicin. Owing to the evolving emergence of MDR towards the currently available therapeutic regimes, the nationwide programmes are being launched for controlling the spread and effective management of TB [4]. Number of factors like slow-acting nature of the drugs, inappropriate doses and treatment durations, incomplete treatments and inadequate health-care systems have been attributed for evolution of drug- resistant TB which ultimately leads to poor compliance and complications in the management of TB [4]. The emergence of Extensive Drug Resistant TB (XDR-TB) has been considered as a more serious threat owing to the resistance of XDR-TB strains towards firstand second-line drugs. The limitations and failure of XDR-TB treatment are more frequently observed in immunocompromised people, especially living with HIV infections [5]. Therefore the emerging MDR and XDR crisis in the mainstream of management of tuberculosis has given a new impulse for searching novel, effective and safe antituberculoid agents.

Exploring natural resources especially medicinal plants has always remained a significant hope in the 'target rich lead poor' scenario of the present-day drug discovery research. Several natural compounds with anti-mycobacterium activity have been described from plants, fungi and marine organisms [6,7].

The first hand information from the traditional healers from the Kinwat and Mahur forest range of Nanded district (MS), India and the circumstantial literature describing the traditional usage of the medicinal plants in the management of infectious diseases was used as a rational for selecting the botanicals for the present study. For example, the folk practitioners traditionally use the Amorphophyllus sylvaticus as a remedy for healing piles, fistula and dental infections and the scientific report describes its broad spectrum activity against Gram-positive and negative bacteria [8]. Of note, majority of fistula abscesses are the result of an acute infection in the internal glands of the anus. Andrographis paniculata commonly called as 'King of Bitter' has been found to be an ingredient of at least 26 Ayurvedic 
Page 2 of 6

formulations against variety of human ailments. Besides suggested remedy against series of human diseases, traditionally it has been also recommended for the treatment of infections associated with diarrhea, dysentery, cholera, pneumonia, swollen lymph nodes, leprosy, bronchitis, sore throats and against variety of chronic and infectious diseases [9]. Besides the traditional applications Corallocarpus epigaeus in the treatment of chronic rheumatism and snake bite, it has been also recommended for the treatment of infectious diseases like dysentery and syphilitic disorders. Currently the Bhil, Meena, Garasia, Damor and Kathodi community, Rajasthan, India uses tubers of Corallocarpus epigaeus for the treatment of typhoid [10].

The tubers of different species of genus Dioscorea such as $D$. oppositifolia, $D$. pentaphylla, D. bulbifera, D. hispida etc. are basically eaten as vegetables by forest inhabiting tribal communities in India [10], however they are also used as traditional medicine to cure different types of diseases including infections associated with piles, syphilis, asthma and ulcers [11]. In Bangladesh, a neighbor country of India, $D$. bulbifera has been traditionally used for the treatment of leprosy: caused by Mycobacterium leprae [11]. Nevertheless, a report from Dschang, Cameroon (Central Africa) demonstrated the efficacy of bulbils of $D$. bulbifera against the M. smegmatis and M. tuberculosis ATCC and MTCS2 strains. In Cameroon, this plant has traditional reputation for treating microbial infections [12]. The tribal communities such as Hill-Kharia, Mankirdia, Santhal, Ho, Kolha, Munda and Bhumi of Odisha state, India traditionally use the parts of D. pentaphylla as a remedy for treating infectious diseases [13]. Perhaps the circumstantial literature and traditional usage inspired us to select different species of Dioscorea for testing against surrogate Mycobaterial strains.

According to Ayurvedic litreture the fresh leaves of Enicostema axillare has been traditionally used as bitter tonic and is a remedy for typhoid and arthritis. The leaves etxatrct of $E$. axillare has been reported to possess broad spectrum antibacterial activity [14]. The tribal communities like menthonni or Karal vatti and kalihari in north India traditionally use the tuber paste of Gloriosa superba for the treatment of leprosy, parasitical infections and remedy for other human diseases. The starch obtained from the tuberous root is given internally in gonorrhoea [15]. In the current literature Morinda citrifolia commonly known as "Noni" and also called as "Indian Mulberry" has established its reputation as health promoting plant. Tribes of Andaman and Nicobar Islands in India, have used the ripe and unripe fruit as food and medicine. Traditionally it is also suggested as remedy for treating dysentery and skin infections, moreover the antibacterial activity of various parts of the plant are well documented [16].

In the present study, above described botanicals were sequentially extracted in water, ethanol and hexane along with their flavonoid and alkaloid fractions. The extracts of the individual plants were further evaluated as possible growth inhibitors of surrogate Mycobacterium strains such as $M$. smegmatis and $M$. phlei. The surrogate Mycobacterium strains are commonly used as alternatives to the virulent species, $M$. tuberculosis, to address the anti-mycobacterial potential of plant extracts and other natural products [17]. We have designed the present studies with a hope of discovering new potential antimycobacterial leads from the selected medicinal plants having reputation as traditional medicines.

\section{Materials and Methods}

\section{Materials}

The Mycobacterium strains such as Mycobacterium smegmatis ( $M$. smegmatis, NCIM 5138 (Figure 1), suggested 'neotype strain' and grows on medium $25 \mathrm{a}$ or $48 \mathrm{a}, 37^{\circ} \mathrm{C}$ ) and Mycobacterium phlei ( $M$. phlei, NCIM 2240 (Figure 2), strain "Crotin" and grows on medium 33, $37^{\circ} \mathrm{C}$ ) were obtained from National Collection of Industrial Microorganisms (NCIM), National Chemical Laboratory Pune (MS), India and were subcultured and maintained onto Lowenstein Jensen media as described previously [18]. Other chemicals like L-asparagine (s.d. fine chemical Ltd. Mumbai), Rifampicin (Himedia Laboratories Pvt. Ltd. Mumbai), solvents, reagents used were of AR grade and were obtained from commercial sources.

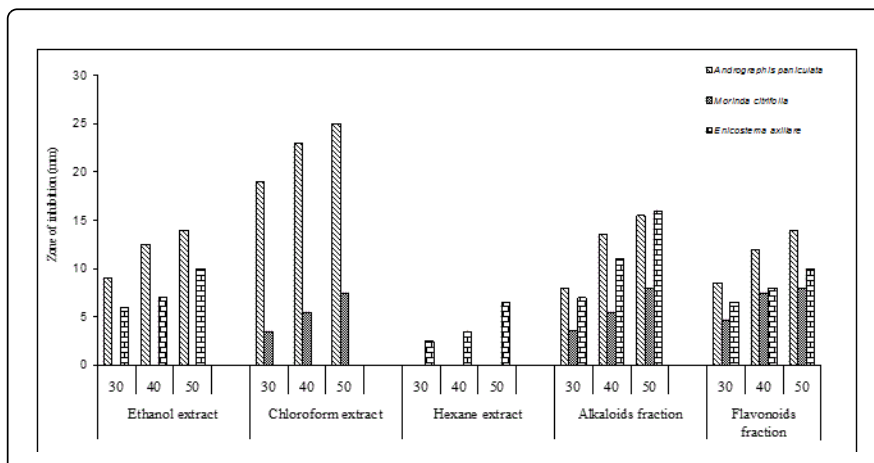

Figure 1: Antimycobacterial effect of different fractions of selected medicinal plants on Mycobacterium smegmatis (NCIM-5138) by agar diffusion method. The antimycobacterial activity was evaluated at $30-50 \mathrm{mg} / \mathrm{ml}$ concentrations of individual fractions of the selected medicinal plants. The result shown here are the mean values of $n=2$.

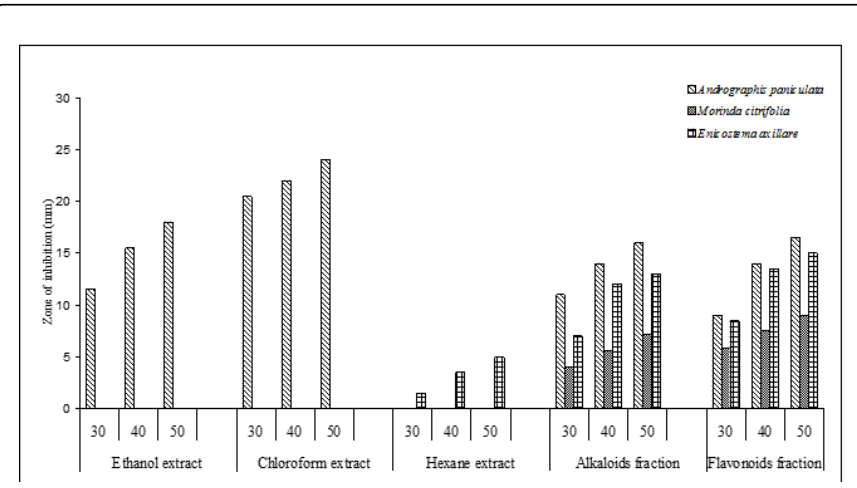

Figure 2: Antimycobacterial effect of different fractions of selected medicinal plants on Mycobacterium phlei (NCIM-2240) by agar diffusion method. The antimycobacterial activity was evaluated at $30-50 \mathrm{mg} / \mathrm{ml}$ concentrations of individual fractions of the selected medicinal plants. The results shown here are the mean values of $\mathrm{n}=2$. 


\section{Collection, identification and preparation of plant material}

The selected medicinal plants such as tubers of Amorphophyllus sylvaticus Roxb Kunth (Araceae) (A9), leaves of Andrographis paniculata Burm Wall (Acanthaceae) (A10), tubers of Corallocarpus epigaeus Rottl and Willd Hook (Cucurbitaceae) (A11), tubers of Dioscorea oppositifolia Linn (Dioscoreaceae) (A12), tubers of Discroia pentaphylla Linn (Dioscoreaceae) (A13), tubers of Dioscorea bulbifera Linn (Dioscoreaceae) (A14), tubers of Dioscorea hispida Dennst (Dioscoreaceae) (A15), whole plant of Enicostema axillare Lam Raynal (Gentianaceae) (A16), tubers of Gloriosa superba Linn (Liliaceae) (A17) and unripe fruits of Morinda citrifolia Linn (Rubiaceae) (A18), were collected from the different localities of Marathwada region (MS), India, in the month of September 2015. The collected plants were identified and authenticated by RNG, Head Department of Botany of the host institute using 'Flora of Marathwada region' [19]. The voucher specimens of the collected plants (A9-A18) were deposited in the Herbarium centre of the host institute. Shade dried, powdered plant samples $(\sim 10 \mathrm{~g})$ were sequentially extracted in water, ethanol, chloroform and hexane using Soxhlet's apparatus up to 8 hours. The solvents were evaporated under reduced pressure at approximately $40^{\circ} \mathrm{C}$ and the extracts were stored in refrigerator until needed for further experiments.

\section{Quantitative determination of the alkaloids and flavonoids}

Estimation of alkaloids content: Quantitative determination of total alkaloids was performed by the method of Harborne [20]. Briefly, $5 \mathrm{~g}$ of the individual plant sample was mixed with $200 \mathrm{ml}$ of $10 \%$ acetic acid (in ethanol) and allowed to stand for $4 \mathrm{~h}$. The cocktail was filtered and the extract was concentrated on a water bath to one-quarter of the original volume. Concentrated ammonium hydroxide was added drop wise to the extract until the precipitation was achieved. The precipitate obtained was washed with dilute ammonium hydroxide and then filtered. The residue of alkaloid was dried and weighed.

\section{Estimation of flavonoids content}

The total flavonoids content was estimated by referring the method of Bohm and Kocipai-Abyazan [16,21]. Briefly, $10 \mathrm{~g}$ of the individual plant sample was extracted repeatedly with $100 \mathrm{ml}$ of $80 \%$ aqueous methanol at room temperature. The solution was filtered through Whatman filter paper No. $42(125 \mathrm{~mm})$. The filtrate was later transferred into a crucible and evaporated up to dryness over a water bath at $600^{\circ} \mathrm{C}$ and weighed.

\section{Determination of antimycobacterial activity of selected plant samples}

Stock solutions of the individual plant extract along with their flavonoid and alkaloid fractions were prepared in $0.5 \%$ dimethyl sulfoxide (DMSO) and diluted to the final concentrations of 30, 40 and $50 \mathrm{mg} / \mathrm{ml}$ in sterilized distilled water. As a part of experimental standardization, initially $1 \mathrm{mg} / \mathrm{ml}$ concentration of plant extract was used for antimycobacterial analysis and it was further extended up to 10 or $20 \mathrm{mg} / \mathrm{ml}$; however no clear zone of inhibition was observed under experimental conditions. Considering the respective results of the optimization experiments, the concentrations of plant extract were kept on higher side $(30-50 \mathrm{mg} / \mathrm{ml}$ ) in order to have clear demonstrable antimycobacterial effects in terms of zone of inhibition [22].
The sensitivity of test Mycobacterium strains to the various fractions of the selected botanicals was demonstrated by agar diffusion method [17]. In short, with help of sterile cork borer $(7 \mathrm{~mm})$ the holes were made into the inoculum seeded solidified nutrient agar medium. A 50 $\mu \mathrm{l}$ volume of individual $(30,40$ and $50 \mathrm{mg} / \mathrm{ml}$ ) plant extracts was loaded into the labeled well in the prepared media plate using sterile pipette. Three parallel sets were carried out simultaneously. The plates thus prepared were kept in a refrigerator for proper prediffusion of the sample and incubated at $37^{\circ} \mathrm{C}$ for 48 hours. Growth of M. smegmatis and $M$. phlei was observed after the incubation of 48 hours and the diameter of inhibition zone was measured subtracting the well size. Rifampicin $(600 \mu \mathrm{g} / \mathrm{ml})$ was used as a standard antibiotic for antimicrobial assay. The activity of rifampicin was not demonstrated by agar diffusion because of whole plate inhibition at $30-50 \mathrm{mg} / \mathrm{ml}$ concentrations.

\section{Determination of the minimum inhibitory concentration (MIC) of the plant extracts}

The MIC of the various plants extract including alkaloids and flavonoids fraction were performed using the broth microdilution assay against the test Mycobacterium strains [23]. Tests were performed in sterile 96 -well microplates by adding a total volume of $200 \mu \mathrm{l}$, comprising $100 \mu \mathrm{l}$ of standardized suspension of either Mycobacterium strains $(1 \times 106$ cells $/ \mathrm{ml})$ and $100 \mu \mathrm{l}$ of different concentrations of plant extracts/alkaloids/flavonoids and incubated up to $48 \mathrm{~h}$ at $37^{\circ} \mathrm{C}$. The plates were observed for microbial growth by measuring the absorbance at $620 \mathrm{~nm}$ using Thermo make Automatic Ex-Microplate Reader (M 51118170). The MIC was defined as the lowest concentration of the sample that inhibited the growth of test microorganisms.

\section{HPTLC profiling}

The finger print of flavonoids and alkaloids of the selected plants were developed using a CAMAG (Germany) make instrumental high performance thin layer chromatography (HPTLC) unit available at Anchrome Pvt. Ltd. Mumbai (MS), India. The flavonoid and alkaloid fractions of the individual sample, $10 \mu \mathrm{l}(2 \mathrm{mg} / \mathrm{ml})$ were spotted separately onto the activated TLC plates using a 'Linomat 5' application system. Rutin hydrate $(1,5$ and $10 \mu \mathrm{g} / \mathrm{ml})$ was used as a marker flavonoid compound. The flavonoids were separated using a mobile phase of ethyl acetate:formic acid:glacial acetic acid:water (100:11:11:27), while alkaloids separation was carried out using a mobile phase of toluene:ethyl acetate:diethyl amine (70:20:10). After running the TLC plates, the Anisaldehyde sulphuric acid reagent and Dragendroff reagent were used as derivatizing agents for flavonoids and alkaloids respectively. After derivatization the spots were visualized under CAMAG UV cabinet (254 and $366 \mathrm{~nm}$ ) and were digitized using CAMAG photo documentation unit [24].

\section{Results}

The amount of total alkaloids present in M. citrifolia, A. paniculata and $E$. axillare were estimated to be $13,26,18 \mathrm{mg} / \mathrm{gm}$ respectively, while the quantity of total flavonoids content was estimated to be and $73.3,54.5$ and $152.3 \mathrm{mg} / \mathrm{gm}$ respectively. The antimycobacterial activity of selected botanicals was demonstrated using agar diffusion assay and the efficacy was calculated in terms of MICs. Amongst the ten selected medicinal plants, only the extracts of $M$. citrifolia, A. paniculata, and $E$. axillare showed antimycobacterial activity against the selected 
Mycobacterium strains (Figures 1-3). No antimycobacterial activity was observed with the water soluble fraction of either of the plant samples. Amongst the plants showing promising anti-mycobaterial activity, the chloroform extract of $A$. paniculata was graded as the most effective antimycobacterial agent against the $M$. smegmatis and $M$. phlei showing MIC values of $10 \mathrm{mg} / \mathrm{ml}$ for both Mycobacterium strains. It is interesting to note that the similar results were observed with the flavonoid fraction of the $A$. paniculata. The alkaloid fractions of $M$. citrifolia, $A$. paniculata, and E. axillare also exhibited significant antimycobacterial activity towards both the strains of Mycobacterium, showing MIC in a range of $10-20 \mathrm{mg} / \mathrm{ml}$. With exception of certain fractions, $M$. citrifolia and $E$. axillare also demonstrated considerable anti-mycobacterium activity with a MIC range of $10-30 \mathrm{mg} / \mathrm{ml}$ (Figure $3)$.

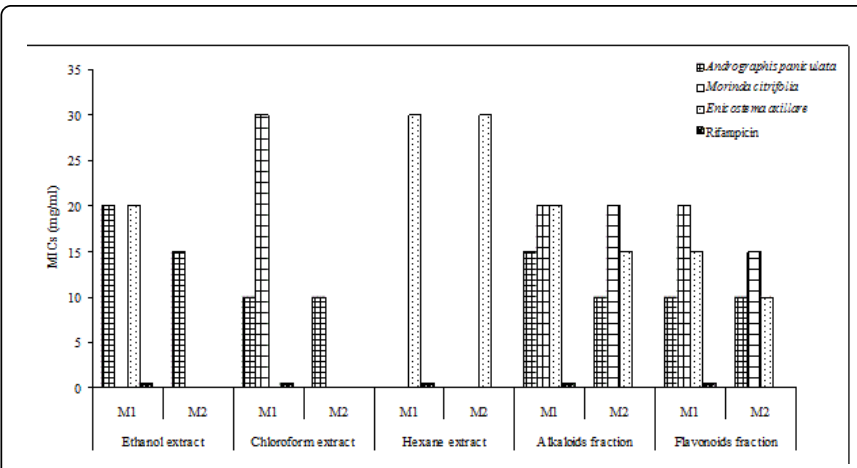

Figure 3: Results of minimum inhibitory concentrations (MICs, $\mathrm{mg} / \mathrm{ml}$ ) of individual fractions of the selected medicinal plants and Rifampicin needed for growth inhibition of Mycobacterium smegmatis (NCIM-5138) and Mycobacterium phlei (NCIM-2240). The MICs were determined by using broth microdilution assay. The results summarised are the mean value of $\mathrm{n}=2, \mathrm{M} 1=M$. smegmatis (NCIM-5138) and M2=M. phlei (NCIM-2240).

The HPTLC fingerprints of flavonoid (Figure 4) and alkaloid fractions (Figure 5) of individual plant samples were carried out along with calculation of the $\mathrm{R}_{\mathrm{f}}$ values (Table 1). The HPTLC analysis of flavonoid fractions of the individual plant samples showed the diversity of flavonoids (Figure 4), but the presence of rutin $\left(R_{f} 0.39\right.$, marker compound) was only observed in E. axillare. However, some of the very close $\mathrm{R}_{\mathrm{f}}$ values such as $0.16,0.18,0.17 ; 0.23,0.28,0.28 ; 0.42$, $0.43,0.39 ; 0.60,0.55,0.56$ and $0.93,0.920 .81$ were observed in the flavonoids fraction of the $M$. citrifolia, A. paniculata and $E$. axillare respectively. The compounds associated with concerned $\mathrm{R}_{\mathrm{f}}$ values shared by these plants might be responsible for showing antimycobacterial activity. The observed $\mathrm{R}_{\mathrm{f}}$ values shared by the flavonoids fraction of the M. citrifolia, A. paniculata and $E$. axillare can be correlated with their MIC values of $20,10,15 \mathrm{mg} / \mathrm{ml}$ for $M$. smegmatis and 15, 10, $10 \mathrm{mg} / \mathrm{ml}$ for $M$. phlei respectively (Table 1).

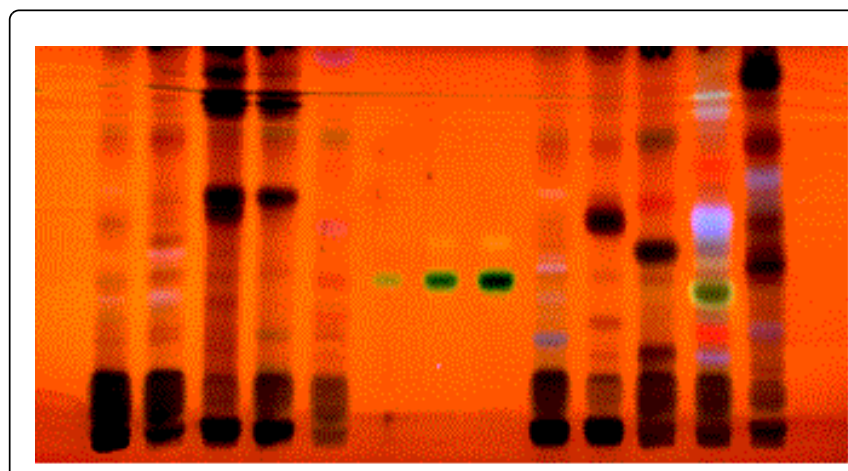

\section{$\begin{array}{llllllllllllll}1 & 2 & 3 & 4 & 5 & 6 & 7 & 8 & 9 & 10 & 11 & 12 & 13\end{array}$}

Figure 4: The digitized image (at $366 \mathrm{~nm}$ ) of HPTLC finger print of flavonoid contents of the selected medicinal plants. (Track no. 1- $D$. oppositifolia, 2- D. pentaphylla, 3- D. Bulbifera, 4- D. hispida, 5- C. epigeous, 6-8- Rutin (1,5 and $10 \mu \mathrm{g}$ ), 9-A. sylvaticus, 10- $G$. superba, 11- M. citrifolia, 12- E. axillare and 13- A. Paniculata.

\begin{tabular}{|c|c|c|c|c|c|c|c|c|c|c|c|}
\hline \multirow[t]{3}{*}{ S.No } & \multirow{3}{*}{$\begin{array}{l}\text { Name of } \\
\text { Plants }\end{array}$} & \multirow{3}{*}{$\begin{array}{l}\text { Name of the } \\
\text { fraction }\end{array}$} & \multicolumn{9}{|c|}{ Band Number (As per the direction of solvent flow) } \\
\hline & & & \multicolumn{9}{|c|}{$\mathbf{R}_{\mathrm{f}}$ values of respective band } \\
\hline & & & 1 & 2 & 3 & 4 & 5 & 6 & 7 & 8 & 9 \\
\hline \multirow[t]{2}{*}{1} & \multirow[t]{2}{*}{ Morinda citrifolia } & Alkaloid & 0.08 & 0.15 & 0.38 & 0.73 & ND & ND & ND & ND & ND \\
\hline & & Flavonoid & $0.16^{*}$ & $0.23^{*}$ & $0.42^{*}$ & 0.48 & $0.60^{*}$ & 0.76 & $0.93^{*}$ & ND & ND \\
\hline \multirow[t]{2}{*}{2} & \multirow{2}{*}{$\begin{array}{l}\text { Andrographis } \\
\text { Paniculata }\end{array}$} & Alkaloid & 0.10 & 0.12 & 0.16 & 0.20 & 0.32 & 0.40 & 0.73 & ND & ND \\
\hline & & Flavonoid & 0.13 & $0.18^{*}$ & $0.28^{*}$ & 0.33 & $0.43^{*}$ & $0.55^{*}$ & 0.63 & 0.66 & $0.92^{*}$ \\
\hline \multirow[t]{2}{*}{3} & \multirow[t]{2}{*}{ Enicostema axillare } & Alkaloid & 0.06 & 0.11 & 0.15 & 0.66 & 0.73 & ND & ND & ND & ND \\
\hline & & Flavonoid & $0.17^{*}$ & 0.21 & $0.28^{*}$ & $0.39^{*}$ & 0.48 & $0.56^{*}$ & 0.67 & $0.81^{*}$ & ND \\
\hline 4 & Marker compound & Rutin & 0.39 & ND & ND & ND & ND & ND & ND & ND & ND \\
\hline
\end{tabular}

Table 1: The ratio of distance travelled by individual fraction to the distance travelled by solvent was calculated as $\mathrm{R}_{\mathrm{f}}$ value. The underlined $\mathrm{R}_{\mathrm{f}}$ value (0.73) indicates the presence of a common compound in the alkaloid fraction of Morinda citrifolia, Andrographis paniculata and 
Enicostema axillare and the $\mathrm{R}_{\mathrm{f}}-0.39$ of Enicostema axillare indicates the presence of rutin in its flavonoid fraction. The values marked as ${ }^{*}$ indicates the presence of similar type of flavonoids shared by M. citrifolia, A. paniculata and E. axillare. ND-Not detected.

The HPTLC fingerprints of alkaloids (Figure 5) of $M$. citrifolia, $A$. paniculata and E. axillare possessing promising antimycobacterial activity have a common unique band of alkaloid $\left(\mathrm{R}_{\mathrm{f}} 0.73\right)$, which possibly might be an active ingredient responsible for imparting antimycobacterial activity. The $\mathrm{R}_{\mathrm{f}} 0.73$ shared by the alkaloid fractions of the $M$. citrifolia, A. paniculata and $E$. axillare can be correlated with their MIC values of $20,15,20 \mathrm{mg} / \mathrm{ml}$ for M. smegmatis and 20,10,15 $\mathrm{mg} / \mathrm{ml}$ for $M$. phlei respectively. Moreover, the HPTLC fingerprints of alkaloid fraction of $A$. paniculata apparently shows more concentration of $\mathrm{R}_{\mathrm{f}} 0.73$ compound, which possibly might be a reason for showing lower MIC values than $M$. citrifolia and $E$. axillare. The above relations clearly demonstrate the possibility of $R_{f} 0.73$ compound as potential antimycobacterial agent. The pharmacological investigations of alkaloids from plant origin are also reported to possess antimicrobial activities $[25,26]$.

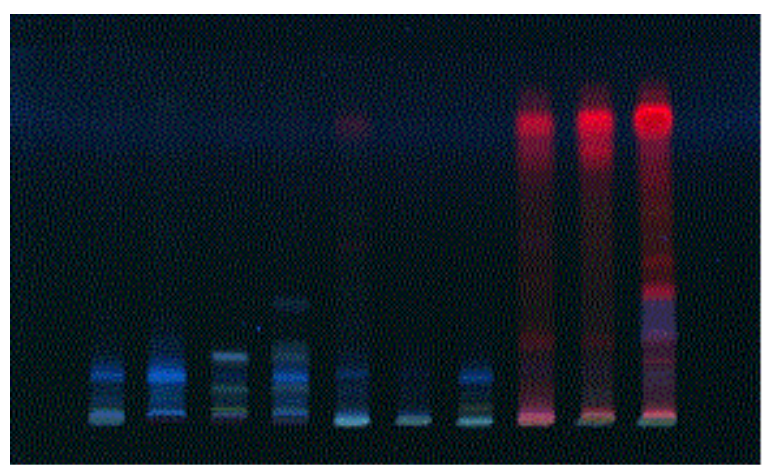

\section{$\begin{array}{llllllllll}1 & 2 & 3 & 4 & 5 & 6 & 7 & 8 & 9 & 10\end{array}$}

Figure 5: The digitized image (at $366 \mathrm{~nm}$ ) of HPTLC finger print of alkaloid contents of selected medicinal plants. (Track no. 1-D. oppositifolia, 2-D. pentaphylla, 3-D. Bulbifera, 4-D. hispida, 5-C. epigeous, 6-A. sylvaticus, 7-G. superba, 8-M. citrifolia, 9-E. axillare and $10-A$. Paniculata.

\section{Discussion}

In general, the difference of activity demonstrated by the selected plant extracts appears to be directly related to the qualitative and/or quantitative diversity of the compounds that are present in the extracts. In the present studies the efficacy of $A$. paniculata seems to be attributed with the presence of high amount of alkaloids $(26 \mathrm{mg} / \mathrm{gm})$ as compared to other samples. The results of the earlier studies [22] for antimycobacterial activity of herbal samples using surrogate Mycobacterium (M. smegmatis and M. fortuitum) species has reported the MIC values up to $60 \mathrm{mg} / \mathrm{ml}$, whereas MIC values of plant extracts under our study ranges from 10 to $30 \mathrm{mg} / \mathrm{ml}$. The results of the earlier studies [22] as well as the present investigation clearly demonstrate the drug resistance in the Mycobacterium strains. Amongst the tested Mycobacterium strains the $M$. smegmatis was observed to be more resistance towards rifampicin ( $\mathrm{MIC}=0.48 \mathrm{mg} / \mathrm{ml}$ ) as compared to $M$. phlei $(\mathrm{MIC}=0.0004 \mathrm{mg} / \mathrm{ml})$, also the same was true for the selected plant samples.
The possible mechanism of anti-mycobacterium activities exhibited by these plants could be traced to the possession of diverse phytochemicals such as alkaloids, flavonoids, saponins, tannins, and other nature phenolic compounds or free hydroxyl groups which are classified as active antimicrobial agents [24]. The HPTLC fingerprint of alkaloids of $M$. citrifolia, $A$. paniculata and $E$. axillare possessing promising anti-mycobacterium activities have a common unique band of alkaloid, which possibly might be the active ingredient responsible for imparting anti-mycobacterium activity. Moreover the pharmacological investigations of alkaloids from plant origin are also reported to possess antimicrobial activities [25,26]. Perhaps, the isolation and characterization of the active principles from these plants might help in translating these medicinal herbs as therapeutic modality.

\section{Conclusion}

In conclusion, the results of the present study clearly demonstrates the efficacy of $A$. paniculata, E. axillare and $M$. citrifolia as growth inhibitors of surrogate Mycobacterium strains such as $M$. smegmatis and $M$. phlei. These plants can be explored for further studies which may result in identification of a novel lead/s arresting the growth of Mycobacterium tuberculosis. The results may find useful in converting these botanicals into therapeutic modalities. Further studies on isolation \& characterization of active principles from the $A$. paniculata, $M$. citrifolia and $E$. axillare and testing them in vitro and in vivo (animal model) against the virulent Mycobacterium tuberculosis are necessary for ascertaining the practical utility of these plants as antituberculoid agents. Nevertheless the results of the present studies hold importance in the midst of MDR-XDR crisis in the management of TB.

\section{Acknowledgement}

The author ADJ gratefully acknowledges the fellowship and the financial support (SSD/SS/040) from Department of Science and Technology, Government of India under the Women's Scientist Project Scheme.

\section{References}

1. Mativandlela NPS, Meyer MJJ, Hussein AA, Houghton JP, Hamilton JC, et al. (2008) Activity against Mycobacterium smegmatis and $M$ tuberculosis by Extract of South African Medicinal Plants. Phytother Res 22: 841-845.

2. Chakraborty AK (2004) Epidemiology of Tuberculosis: Current status in India. Indian J Med Res 120: 248-276.

3. Wayne LG, Kubica GP (1986) Genus Mycobacteria in Bergey's Manual Systematic Bacteriology. Sneath PHA, Mair NJ, Sharpe ME, Holt JG (Ed), Cilliams and Wilkins, London 2: 1436-1457.

4. Sacchettini JC, Rubin EJ, Freundlich JS (2008) Drugs versus bugs: In pursuit of the persistent predator Mycobacterium tuberculosis. Nature Rev Microbiol 6: 41-52.

5. WHO Fact Sheet (2006) XDR-TB (Extensive Drug Resistant TB).

6. Lewis K (1999) Multidrug resistance: Versatile drug sensors of bacterial cells. Curr Biol 9: 403-407.

7. Pauli GF, Case RJ, Inuit T, Wang Y, Cho S, et al. (2005) New perspectives on natural products in TB drug research. Life Sci 78: 485-494. 
Citation: Rajesh NG, Archana DJ (2017) Anti-mycobacterial Activity of Selected Indian Botanicals Using Surrogate Mycobacterium Strains. Nat Prod Chem Res 5: 279. doi:10.4172/2329-6836.1000279

Page 6 of 6

8. Revathi E, Rani G (2014) Antimicrobial Potential activity of Amorphophallus sylvaticus extract against oral microorganism. Intern J Innov Pharma Biosci Res Technol 1: 38-46.

9. Niranjan A, Tiwari SK, Lehri A (2010) Biological activities of Kalmegh (Andrographis paniculata Nees) and its active principles-a review. Indian J Natu Prod Resour 1: 125-135.

10. Swarnkar S, Kaetewa SS (2008) Ethnobotanical observation on tuberous plants tribal area of Rajasthan. Ethnobot Lf 12: 647-666.

11. Mbiantcha M, Kamanyi A, Teponno RB, Tapondjou AL, Watcho P, et al. (2011) Analgesic and anti- inflammatory properties of extracts from the bulbils of Dioscorea bulbifera L. var sativa (Dioscoreaceae) in Mice and Rats. Evidence based Complem Altern Med G12935: 9.

12. Kuete V, Betrand Teponno R, Tsafack Mbaveng A (2011) Antibacterial activities of the extracts, fractions and compounds from Dioscorea bulbifera. BMC Complem Altern Med 12: 228.

13. Kumar S, Behera SP, Jena KP (2013) Validation of tribal claims on Dioscorea pentaphylla $L$. through phytochemical screening and evaluation of antibacterial activity. Plant Sci Res 35: 55-61.

14. Deore SL, Khadabadi SS, Bhagure L, Ghorpade DS (2008) In vitro antimicrobial and antioxidant studies on Enicostemma axillare (Lam.) Reynal leaves. Natu Prod Rad 7: 409-412.

15. Prakash JW, Anpin Raja RD, Asbin Anderson N (2008) Ethnomedicinal plants used by Kani tribes of Agasthiyarmalai biosphere reserve, southern Western Ghats. Indian J Tradition Knowled 7: 410-413.

16. Usha R, Sashidharan S, Palaniswamy M (2010) Antimicrobial Activity of a Rarely Known Species, Morinda citrifolia L. Ethnobotanical Leaflets 14: 306- 311 .
17. Gautam RA, Saklani K, Jachak SM (2007) Indian medicinal plants as a source of antimycobacterial agents. J Ethnopharmacol 110: 200-234.

18. Chaturvedi V, Dwivedi N, Tripathi PR, Sinha S (2007) Evaluation of Mycobacterium smegmatis as a possible surrogate screen for selecting molecules active against multi-drug resistant Mycobacterium tuberculosis. J Gen Appl Microbiol 53: 333-337.

19. Naik VN (1998) Flora of Marathwada. Natu Prod Rad 5: 40-43.

20. Harborne JB (1973) Phytochemical methods. London, Chapman and Hall. 3: 49-188.

21. Boham BA, Kocipai-Abyazan R (1974) Flavonoids and condensed tannins from leaves of Hawaiian vaccinium vaticulatum and $\mathrm{V}$. calycinium. Pacific Sci 48: 458-463.

22. Michelle M, Enzo AP (2008) Anti-Mycobacterial activity of extracts derived from Australian Medicinal Plants. Res J Microbiol 3: 535-538.

23. Rojas A, Hernandez L, Pereda-Miranda R, Mata R (1992) Screening for antimicrobial activity of crude drug extracts and pure natural products from Mexican medicinal plants. J Ethonopharmacol 35: 275-283.

24. Agarwal H, Kaul N, Paradkar AR, Mahadik KR (2004) HPTLC method for guggulsterone: I. Quantitative determination of E- and Zguggulsterone in herbal extract and pharmaceutical dosage form. J Pharm Biomed Anal 36: 33-41.

25. Clark AM, McChesney JD, Adams RP (1990) Antimicrobial properties of heartwood, bark/sapwood and leaves of Juniperus species. Phytother Res 4: 22-28.

26. Chowdhury D, Sayeed A, Islam A (2002) Antimicrobial activity and cytotoxicity of Aerva lanata. Fitoterapia 73: 92-94. 